\title{
Review Article \\ Tsetse Flies (Glossina) as Vectors of Human African Trypanosomiasis: A Review
}

\author{
Florence Njeri Wamwiri and Robert Emojong Changasi \\ Kenya Agricultural and Livestock Research Organisation, Biotechnology Research Institute, P.O. Box 362, Muguga 00902, Kenya \\ Correspondence should be addressed to Florence Njeri Wamwiri; f.wamwiri@gmail.com
}

Received 5 November 2015; Revised 2 February 2016; Accepted 4 February 2016

Academic Editor: Carlos E. Almeida

Copyright (c) 2016 F. N. Wamwiri and R. E. Changasi. This is an open access article distributed under the Creative Commons Attribution License, which permits unrestricted use, distribution, and reproduction in any medium, provided the original work is properly cited.

\begin{abstract}
Human African Trypanosomiasis (HAT) transmitted by the tsetse fly continues to be a public health issue, despite more than a century of research. There are two types of the disease, the chronic gambiense and the acute rhodesiense-HAT. Fly abundance and distribution have been affected by changes in land-use patterns and climate. However, disease transmission still continues. Here, we review some aspects of HAT ecoepidemiology in the context of altered infestation patterns and maintenance of the transmission cycle as well as emerging options in disease and vector control.
\end{abstract}

\section{Introduction}

African trypanosomiasis is one of a diverse range of neglected tropical diseases. The tsetse fly, Glossina sp. is the main vector for trypanosomes, the parasites that cause trypanosomiasis. This disease affects both humans and livestock. In humans, the disease is known as sleeping sickness or Human African Trypanosomiasis (HAT) while, in livestock, it is referred to as nagana or African Animal Trypanosomiasis (AAT). AAT is widespread across most of the 38 countries of sub-Saharan Africa that are considered endemic for tsetse flies and the disease [1] and is considered to be a major factor limiting agricultural production [2]. On the other hand, HAT occurs as a highly focal disease [3]. Both the disease and its vector have been the focus of intense scientific interest since David Bruce first described the link between tsetse flies and HAT [4]. In spite of this, trypanosomosis continues to be a constraint to livestock-based rural livelihoods and a potentially fatal human disease [5].

\section{Epidemiology of Sleeping Sickness}

There are two distinct forms of sleeping sickness, with differences in aetiology, epidemiology, clinical manifestation, and treatment regimes. The chronic anthroponotic form which is caused by Trypanosoma brucei gambiense (gHAT) occurs in
24 countries in west and central Africa and accounts for about 98\% of reported cases (WHO Technical Report 2012). The Democratic Republic of Congo (DRC) continues to report the highest number of $g$ HAT cases, contributing up to $84 \%$ of endemic cases reported in 2012 [6]. The acute zoonotic form of the disease caused by $T$. $b$. rhodesiense is termed as rhodesiense-HAT ( $r \mathrm{HAT}$ ) and is found in 13 countries in eastern and southern Africa. Less than $2 \%$ of reported HAT cases are due to T. $b$. rhodesiense [7]. Uganda has the distinction of being the only country with both $r$ HAT and gHAT; however, the incidence foci of two diseases are spatially distinct and no convergence of the two disease zones has been observed yet [8].

2.1. Disease Transmission Cycle. The transmission cycle of gambiense-HAT ( $g$ HAT) is most commonly considered to be human-fly-human. It is thought that, in the presence of the vector, the long duration of $g$ HAT infection in humans is sufficient to maintain the transmission cycle. This forms the basis of the traditional screen-and-treat approach to gHAT control. A possible animal reservoir has been suggested in the epidemiology of $g \mathrm{HAT}$, but its contribution to disease transmission remains unclear. Indeed, surveys conducted in $g$ HAT foci indicate the presence of no or very few T. $b$. gambiense infections in livestock or wild animals $[9,10]$. Additionally, it has been possible to locally eliminate T. $b$. 
gambiense transmission by treatment of the human reservoir alone, without recourse to animal targeted interventions [11]. However, the involvement of animals in this cycle cannot be completely ruled out. It has been suggested that sustainable control of AAT is an indispensable approach towards achieving gHAT elimination in west and central Africa [12].

On the other hand, the transmission of $r$ HAT relies on the presence of vertebrate reservoirs comprising both domestic and wild animals [13] and the cycle is typically animaltsetse-animal/human. However, during epidemics when the number of infected persons is relatively high, the transmission cycle may follow the route human-tsetse-human [14]. In eastern and southern Africa, numerous wildlife species living in conservation areas serve to maintain the disease reservoir. As a result, some of the people infected do so in or around the game parks or reserves [15]. In the period 19902007, 49 nonendemic cases were documented; principally tourists who were presumably exposed to tsetse bites in game parks in Kenya, Malawi, Tanzania, Uganda, Zambia, and Zimbabwe (reviewed by [16]). Although wild animals are the key reservoirs in these game parks, investigations reveal low infection rates and low parasitaemia levels with humaninfective trypanosomes [17]. For instance, a recent study conducted within Zambia's Luangwa Valley found a paltry $0.5 \%$ $(n=418) T . b$. rhodesiense infection prevalence in surveyed wildlife [18]. Livestock in low endemicity foci exhibit a correspondingly low prevalence of T. $b$. rhodesiense, but this can be enough to cause a flare-up of the disease. The emergence of HAT in northern Uganda has been linked to the introduction of infected cattle from endemic southern areas in a restocking programme [19] and highlights the important role of veterinary policy in mitigating the effects of zoonotic disease [20].

2.2. Trends in Numbers of Reported Cases. The incidence of sleeping sickness has been declining over the years, falling from circa 26,000 cases reported in 2000 to less than 8,000 cases reported in 2012. Specifically, the number of $g$ HAT and $r$ HAT cases reported to WHO in this period decreased by $75.9 \%$ and $87.9 \%$, respectively [14]. This decrease is attributed to improved case detection and treatment and vector management [21]. Despite this decreased incidence, it is estimated that up to 70 million people distributed over 1.5 million $\mathrm{km}^{2}$ remain at risk of contracting the disease [22].

2.3. Effect of Changes in Land-Use and Climate on Disease Risk and Incidence. Rising population levels in many parts of sub-Saharan Africa have caused increased land pressure, pushing more people into tsetse infested marginal areas. This immigration has led to one of two outcomes: (i) elimination of tsetse habitat, hence disappearance of tsetse flies and apparent elimination of the disease [23], or (ii) increased human-fly contact, leading to increased risk of contracting trypanosomiasis [24]. Simulation models have suggested that population growth will cause a decline of savannah and forest tsetse, with possible extinction in eastern and southern Africa [25]. In these regions, tsetse populations have been confined to discrete habitats, with a high abundance in and around wildlife conservation areas such as game parks and reserves.
Such conservation areas provide suitable conditions for tsetse survival and function as breeding sites. With increased human encroachment into protected areas, there is bound to be an increased disease risk [26], at least in the initial period of settlement.

Transmission of vector-borne diseases, including trypanosomiasis, is influenced by the environment, and any changes in that environment may affect the disease, hence their impact on health and the economy [27]. In traditional HAT foci, environmental and biological conditions are ideal for the coexistence and interaction of the vector, the host, and the parasites, thus permitting disease transmission to take place. Factors that affect the resting sites for adult tsetse flies, such as long-term changes in rainfall and temperature, can have a significant effect on the epidemiology and transmission of trypanosomiasis [28]. In both Burkina Faso and Mali decreased rainfall and increased human density have been implicated in the contraction of previously documented tsetse habitat limits [29]. Further, fragmentation of the tsetse habitat has important effects on fly population dynamics and has been shown to reduce tsetse apparent densities [18].

Landscape features and livestock and human mobility are all important predictors of HAT incidence as they influence fly presence, density, and dispersal [30]. Social, cultural, and economic factors also affect outcomes in disease incidence. A comparative analysis of socioeconomic and cultural determinants of HAT in four adjacent foci on the boundary of KenyaUganda border concluded that knowledge of tsetse and its control, culture, farming practices, and demographic and socioeconomic variables explained occurrence of HAT better than landscape features [31]. These sociocultural practices may also be used to explain the phenomenon of sleeping sickness patients presenting in urban health centers, particularly in the gHAT foci of central Africa. Palpalis group tsetse, of which the G. fuscipes subspecies are estimated to be responsible for about $90 \%$ of all HAT cases [32] inhabit fairly conserved riparian environments [31, 33]. The flies of this group are able to adapt to and easily colonize peridomestic habitats [25], including suburban areas surrounding cities, for example, Kinshasa, Libreville, Bonon, and Bangui [34, 35]. These foci have been termed as "rural foci with urban manifestation" whereby infection does not typically occur within the city limits, but people get infected in the course of their forays into the tsetse-infested periphery of the city [36].

\section{Tsetse Flies as Vectors of Human-Infective Trypanosomes}

Tsetse flies can be grouped into three main subgroups depending on the environment they inhabit: thus, riverine (palpalis), savannah (morsitans), or forest-dwelling tsetse (fusca). All tsetse species are capable of transmitting human-infective trypanosomes. However, the major species involved in HAT transmission are the palpalis group tsetse, specifically $G$. palpalis spp and G. fuscipes spp. Sleeping sickness occurs in geographically delineated zones referred to as "foci" [37]. Such foci are often infested by sympatric species, whereby one species is the predominant one $[38,39]$. Flies pick up bloodstream parasites from their hosts: livestock, wildlife, and 
humans. Vectorial capacity describes the innate ability of a specific fly species to acquire, mature, and transmit trypanosomes. Different tsetse species coinfesting the same habitat often have varying vectorial capacities for human-infective trypanosomes [40, 41]. For this reason, it is important to determine the infection prevalence in sympatric tsetse species so as to identify which species are key in disease transmission. Such data can then be used to inform decisions on control interventions. In addition, infection prevalence data helps scientists to better understand transmission dynamics and detect spatiotemporal trends, both of which have important implications for disease control [42]. However, in nature, the prevalence of human-infective trypanosomes in tsetse flies, as detected by parasitological methods (dissection and microscopy), is often very low [42], even in active foci $[43,44]$. The classical dissection/microscopy technique [45] though labour-intensive may be the only tool available to determine infection rates in the field. Using dissection, T. brucei infections are indicated by the presence of trypanosomes in the salivary glands. This procedure however has disadvantages in that it requires skilled technicians and has a low diagnostic sensitivity $[42,46,47]$. In many cases, dissection results do not vary much in epidemic or endemic situations and is often less than $1 \%$, despite available evidence of active infections in animals or humans $[42,48-50]$. The PCR technique is frequently applied to detect parasite DNA in disease vectors $[51,52]$. However, the presence of parasite DNA does not indicate the presence of a mature, transmissible infection and therefore is not a direct indicator of risk [42]. Often, PCR gives a misleading overestimation of fly infection as compared to dissection results. This is because PCR detects trypanosome DNA and will not differentiate between an active transmissible infection in the fly and a recent infective feed. This therefore necessitates the development and use of novel methods to corelate prevalence with disease risk.

\section{Emerging Options in Disease and Vector Control}

Despite considerable investments towards its control and/or eradication, tsetse and trypanosomiasis still remain a major public health issue. The control of sleeping sickness hinges on two key aspects: disease control and vector control. Recent and ongoing improvements to these two aspects are contributing to attainment of the WHO target for disease elimination.

\subsection{Integration of HAT Diagnosis and Treatment into National} Primary Health Care Systems. The resurgence of sleeping sickness in countries such as Sudan, Angola, and the DRC has been attributed to political and civil unrest which has resulted in mass migration of populations into risk situations and the breakdown of traditional government support and disease control systems [53]. In many of these countries, disease surveillance and control activities are highly dependent on foreign aid, including nongovernmental aid agencies $[54,55]$. The reduction or/and cessation of foreign aid can affect control activities, leading to flare-ups of the disease. In the case of DRC, a dramatic upsurge in number of cases (up to
25,000 cases annually) was experienced when Belgian bilateral aid funding disease surveillance and treatment activities was terminated in 1990. The trend was reversed with the resumption of bilateral aid in 1998, and the subsequent continuation of large scale screening activities and treatment programmes [56]. To reduce dependency on foreign aid for HAT control, endemic countries are being encouraged and supported to take up ownership of the control process [57]. Towards this, efforts have been made towards integration of disease diagnosis and treatment activities at government primary health care centers [58].

4.2. Improved Diagnostic Tools. Substantial progress has also been made towards the development and routine application of improved diagnostic tools in endemic countries. These include novel and/improved techniques, for example, those incorporating the use of light-emitting diode fluorescence microscopy [59], Loop-Mediated Isothermal Amplification (LAMP) technique [60], and individual Rapid Diagnostic Tests (RDTs) [61] are currently undergoing evaluation towards routine usage as point-of-care tests [62]. In addition, new algorithms are being developed to shorten time-totreatment for $g$ HAT [63] which effectively reduces the possibility of onward transmission. Another development towards improved HAT control has been compilation of disease distribution maps for HAT, taking advantage of the focal nature of the disease to compile comprehensive village-level maps of HAT distribution as an essential tool for disease control, research, and advocacy [7]. The HAT Atlas provides a valuable contribution towards informed decision-making for planning and monitoring of control activities and assessment of epidemiological trends as well as research activities.

4.3. Inclusion of Vector Management Strategies as a Key Component of gHAT Control. It has long been widely accepted that tsetse control plays a central role in controlling the zoonotic $r$ HAT [64]. However, epidemiologists now concur that vector control is required in the management of $g \mathrm{HAT}$ as well $[44,65]$. Indeed, the implementation of vector control strategies along with medical interventions (screen and treat) in several $g$ HAT foci, including Mandoul (Chad), northwestern Uganda, and Boffa (Guinea), has significantly reduced the incidence of new cases $[66,67]$. The necessity of vector control is also supported by the chronic nature of $g \mathrm{HAT}$ infection, with one case reportedly presenting as long as 29 years after the initial infection [68]. In the presence of the vector, such an asymptomatic carrier may have an important potential role in disease transmission. There have been considerable advances made in the search for efficient and costeffective control tools against riverine tsetse involved in the transmission of $g$ HAT [21]. This search has culminated in the development of so-called "tiny targets" [69]. These insecticide-treated targets are much smaller $(25 \mathrm{~cm} \times 50 \mathrm{~cm})$ than the traditional $1 \times 1 \mathrm{~m}$ targets. Despite their size, tiny targets have proved to be quite effective for the control of riverine tsetse, specifically G. fuscipes spp. and G. palpalis spp. $[70,71]$. In addition, they cost much less due to their smaller size (hence reduced costs for impregnation and materials). In 
addition, due to their light weight, they can be easily deployed by foot, or using bicycles and motorcycles [72]. Further, tiny targets when mounted on pirogues moving along a river have proved to be effective in reducing tsetse density [73]. The development of such novel control tools, as well as standardization of existing models, will lead to identification of cost-effective devices for tsetse management $[70,74,75]$.

\subsection{Adoption of the "One Health" Concept in HAT Control.} Increasingly, integrated strategies that use interdisciplinary study and action to address control of both HAT and AAT simultaneously are being promoted. This approach of controlling pests of veterinary importance that transmit zoonotic agents is an example of the "One Health" concept, where a single vector control technique mitigates the risk for transmission of two diseases. Indeed, the WHO specifically recommends that surveillance and control of $r$ HAT should be coordinated with veterinary services in a "One Health" approach [76]. Today, this strategy has been widely applied in both $g$ HAT and $r$ HAT foci to decrease tsetse density, thereby reducing human-tsetse contact and proving that simultaneous control of both AAT and HAT has a bigger impact on disease incidence [77-79].

4.5. Vector Control in Protected Areas. In eastern and southern Africa, the distribution of tsetse flies is increasingly confined to protected areas such as game parks and reserves. These parks, due to their suitable vegetative cover and array of available host species, act as tsetse breeding sites and a large number of current rhodesiense foci are allied to game parks. This situation has resulted in increased risk and incidence of $r$ HAT infection among tourists and game park staff [80], forcing some countries to implement tsetse control in game parks. In collaboration with tsetse control experts, wildlife authorities have instituted measures to reduce human-fly contact including aerial spraying, installation of impregnated traps, and targets/screens and spraying of vehicles on park exit [8183]. Such interventions may be successful if they are sustained for prolonged periods of time and should therefore be promoted.

4.6. Future Control Options Using a Paratransgenic Approach. Another development towards vector management in HAT control comes from the field of genetic modification. Arthropod research has revealed the presence of symbionts involved in the suppression of pathogenic organisms [84-86] and which can be manipulated to express foreign proteins designed to block pathogen transmission [87]. This strategy, known as paratransgenesis, has been developed and proposed to combat different insect-borne animal and human diseases $[85,88-90]$. The paratransgenic approach has been proposed as a strategy for inhibiting trypanosome survival, development, and maturation in tsetse and therefore interference with transmission of African sleeping sickness [91]. The tsetse symbiont, S. glossinidius, has been shown to influence vector competence, at least in some fly species [92-96]. For this reason, this bacterium is considered as a potential in vivo drug delivery vehicle to control trypanosome development in the fly [97]. The availability of in vitro cultures of S. glossinidius has enabled development of genetic transformation systems that introduce and express foreign products in Sodalis and subsequently into host insects [85]. Along this line, Belgian researchers have successfully genetically modified Sodalis to express antitrypanosomal genes that specifically target bloodstream parasites. This is a proof-of-concept that indeed the Sodalis bacterium is able to express and release a sufficient amount of active, functional, parasite-targeting compound [97]. This discovery provides a promising avenue in the fight against tsetse-transmitted trypanosomiasis.

\section{Future Prospects}

After more than 100 years of tsetse and trypanosomiasis research, the prognosis of the disease remains ambiguous. There is a prominent idea that vector eradication may be impossible to achieve, even with sustained integrated approaches but these may be enough to maintain high levels of suppression [98]. In addition, it is thought that elimination of $T$. brucei rhodesiense is unlikely due to its extensive zoonotic distribution. Given that, future research towards disease control should focus on improvement of vector control methods, cost-effective disease surveillance, and early case detection and treatment [78]. However, some outlooks are generally more positive. The WHO, by including HAT in its roadmap for "Eradication, Elimination, and Control of Neglected Tropical Diseases" has set a target to eliminate HAT as a public health problem by 2020 , when fewer than one new case $/ 10,000$ inhabitants in at least $90 \%$ of endemic foci is expected [76]. It is argued that transfer of all the accumulated scientific knowledge on tsetse and HAT from the bench to the field will lead to effective diagnosis, treatment and vector control interventions [99]. In particular, the elimination of $g$ HAT is considered feasible because of "the epidemiological vulnerability of the disease, the current state of control, the availability of strategies and tools, and international commitment and political will” [14].

\section{Conflict of Interests}

The authors declare that there is no conflict of interests regarding the publication of this paper.

\section{Acknowledgment}

The authors acknowledge the Director (KALRO) for permission to publish this paper.

\section{References}

[1] G. Cecchi, M. Paone, U. Feldmann, M. J. Vreysen, O. Diall, and R. C. Mattioli, "Assembling a geospatial database of tsetsetransmitted animal trypanosomosis for Africa," Parasites and Vectors, vol. 7, article 39, 2014.

[2] A. P. M. Shaw, G. Cecchi, G. R. W. Wint, R. C. Mattioli, and T. P. Robinson, "Mapping the economic benefits to livestock keepers from intervening against bovine trypanosomosis in Eastern 
Africa," Preventive Veterinary Medicine, vol. 113, no. 2, pp. 197210, 2014.

[3] G. Cecchi, M. Paone, J. R. Franco et al., "Towards the Atlas of human African trypanosomiasis," International Journal of Health Geographics, vol. 8, article 15, 2009.

[4] D. Bruce, Preliminary Report on the Tsetse Fly Disease or Nagana in Zululand, Bennett \& Davis, Durban, South Africa, 1895.

[5] R. Allsopp, "Options for vector control against trypanosomiasis in Africa," Trends in Parasitology, vol. 17, no. 1, pp. 15-19, 2001.

[6] C. Lumbala, P. P. Simarro, G. Cecchi et al., "Human African trypanosomiasis in the Democratic Republic of the Congo: disease distribution and risk," International Journal of Health Geographics, vol. 14, no. 1, article 20, 2015.

[7] P. P. Simarro, G. Cecchi, M. Paone et al., "The Atlas of human African trypanosomiasis: a contribution to global mapping of neglected tropical diseases," International Journal of Health Geographics, vol. 9, article 57, 2010.

[8] R. Echodu, M. Sistrom, C. Hyseni et al., "Genetically distinct Glossina fuscipes fuscipes populations in the lake Kyoga region of Uganda and its relevance for human African trypanosomiasis," BioMed Research International, vol. 2013, Article ID 614721, 12 pages, 2013.

[9] A. S. P. Balyeidhusa, F. A. S. Kironde, and J. C. K. Enyaru, "Apparent lack of a domestic animal reservoir in Gambiense sleeping sickness in northwest Uganda," Veterinary Parasitology, vol. 187, no. 1-2, pp. 157-167, 2012.

[10] F. Njiokou, C. Laveissière, G. Simo et al., "Wild fauna as a probable animal reservoir for Trypanosoma brucei gambiense in Cameroon," Infection, Genetics and Evolution, vol. 6, no. 2, pp. 147-153, 2006.

[11] J. Pépin and H. A. Méda, "The epidemiology and control of human African trypanosomiasis," Advances in Parasitology, vol. 49, pp. 71-132, 2001.

[12] G. Simo and J. B. Rayaisse, "Challenges facing the elimination of sleeping sickness in west and central Africa: sustainable control of animal trypanosomiasis as an indispensable approach to achieve the goal," Parasites \& Vectors, vol. 8, article 640, 2015.

[13] F. N. Wamwiri, G. Nkwengulila, and P.-H. Clausen, "Hosts of Glossina fuscipes fuscipes and G. pallidipes in areas of western Kenya with endemic sleeping sickness, as determined using an egg-yolk (IgY) ELISA," Annals of Tropical Medicine and Parasitology, vol. 101, no. 3, pp. 225-232, 2007.

[14] J. R. Franco, P. P. Simarro, A. Diarra, and J. G. Jannin, "Epidemiology of human African trypanosomiasis," Clinical Epidemiology, vol. 6, no. 1, pp. 257-275, 2014.

[15] B. Namangala, L. Hachaambwa, K. Kajino et al., "The use of Loop-mediated Isothermal Amplification (LAMP) to detect the re-emerging Human African Trypanosomiasis (HAT) in the Luangwa and Zambezi valleys," Parasit Vectors, vol. 4, no. 5, p. 282, 2012.

[16] S. J. Migchelsen, P. Büscher, A. I. M. Hoepelman, H. D. F. H. Schallig, and E. R. Adams, "Human African trypanosomiasis: a review of non-endemic cases in the past 20 years," International Journal of Infectious Diseases, vol. 15, no. 8, pp. e517-e524, 2011.

[17] H. M. Munang’andu, V. Siamudaala, M. Munyeme, and K. S. Nalubamba, "A review of ecological factors associated with the epidemiology of wildlife trypanosomiasis in the Luangwa and Zambezi valley ecosystems of Zambia," Interdisciplinary Perspectives on Infectious Diseases, vol. 2012, Article ID 372523, 13 pages, 2012.
[18] N. E. Anderson, J. Mubanga, E. M. Fevre et al., "Characterisation of the wildlife reservoir community for human and animal trypanosomiasis in the Luangwa Valley, Zambia," PLoS Neglected Tropical Diseases, vol. 5, no. 6, Article ID e1211, 2011.

[19] E. M. Fèvre, P. G. Coleman, M. Odiit, J. W. Magona, S. C. Welburn, and M. E. J. Woolhouse, "The origins of a new Trypanosoma brucei rhodesiense sleeping sickness outbreak in eastern Uganda," The Lancet, vol. 358, no. 9282, pp. 625-628, 2001.

[20] E. Fevre, J. Magona, P. Coleman, M. Woolhouse, and S. Welburn, "Livestock demography and the risk of spread of $T$. b. rhodesiense in Uganda: implications for policy," Integrated Control of Pathogenic Trypanosomes and Their Vectors, vol. 8, pp. 21-22, 2003.

[21] P. P. Simarro, J. Jannin, and P. Cattand, "Eliminating human African trypanosomiasis: where do we stand and what comes next?" PLoS Medicine, vol. 5, no. 2, pp. 174-180, 2008.

[22] P. P. Simarro, G. Cecchi, J. R. Franco et al., "Estimating and mapping the population at risk of sleeping sickness," PLoS Neglected Tropical Diseases, vol. 6, no. 10, Article ID e1859, 2012.

[23] V. Mwanakasale and P. Songolo, "Disappearance of some human African trypanosomiasis transmission foci in Zambia in the absence of a tsetse fly and trypanosomiasis control program over a period of forty years," Transactions of the Royal Society of Tropical Medicine \& Hygiene, vol. 105, no. 3, pp. 167-172, 2011.

[24] S. De La Rocque, X. Augusseau, S. Guillobez et al., "The changing distribution of two riverine tsetse flies over 15 years in an increasingly cultivated area of Burkina Faso," Bulletin of Entomological Research, vol. 91, no. 3, pp. 157-166, 2001.

[25] R. S. Reid, R. L. Kruska, U. Deichmann, P. K. Thornton, and S. G. A. Leak, "Human population growth and the extinction of the tsetse fly," Agriculture, Ecosystems and Environment, vol. 77, no. 3, pp. 227-236, 2000.

[26] B. A. Jones, D. Grace, R. Kock et al., "Zoonosis emergence linked to agricultural intensification and environmental change," Proceedings of the National Academy of Sciences of the United States of America, vol. 110, no. 21, pp. 8399-8404, 2013.

[27] A. Engering, L. Hogerwerf, and J. Slingenbergh, "Pathogenhost-environment interplay and disease emergence," Emerging Microbes and Infections, vol. 2, article e5, 2013.

[28] L. E. G. Mboera, B. K. Mayala, E. J. Kweka, and H. D. Mazigo, "Impact of climate change on human health and health systems in Tanzania: a review," Tanzania Journal of Health Research, vol. 13, supplement 1, no. 5, pp. 407-426, 2011.

[29] F. Courtin, J.-B. Rayaissé, I. Tamboura et al., "Updating the northern tsetse limit in Burkina Faso (1949-2009): impact of global change," International Journal of Environmental Research \& Public Health, vol. 7, no. 4, pp. 1708-1719, 2010.

[30] F. Courtin, V. Jamonneau, G. Duvallet et al., "Sleeping sickness in West Africa (1906-2006): changes in spatial repartition and lessons from the past," Tropical Medicine and International Health, vol. 13, no. 3, pp. 334-344, 2008.

[31] J. J. Rutto, O. Osano, E. G. Thuranira, R. K. Kurgat, and V. A. O. Odenyo, "Socio-economic and cultural determinants of human African trypanosomiasis at the Kenya-Uganda transboundary," PLoS Neglected Tropical Diseases, vol. 7, no. 4, Article ID e2186, 2013.

[32] WHO, Research Priorities for Chagas Disease, Human African Trypanosomiasis and Leishmaniasis, WHO Technical Report Series, WHO, 2012.

[33] U. Alam, C. Hyseni, R. E. Symula et al., "Microfauna-host interactions: implications for trypanosome transmission dynamics 
in Glossina fuscipes fuscipes in Uganda," Applied and Environmental Microbiology, vol. 78, no. 13, pp. 4627-4637, 2012.

[34] L. K. Tongue, J. F. Mavoungou, R. G. Kamkumo et al., "Human African trypanosomiasis in suburban and urban areas: a potential challenge in the fight against the disease," Journal of Clinical \& Experimental Pathology, vol. 3, article 002, 2012.

[35] F. Courtin, I. Sidibé, J. Rouamba, V. Jamonneau, A. Gouro, and P. Solano, "Population growth and global warming: impacts on tsetse and trypanosomoses in West Africa," Parasite, vol. 16, no. 1, pp. 3-10, 2009.

[36] F. Courtin, S. Dupont, D. Zeze et al., "Human African trypanosomiasis: urban transmission in the focus of Bonon (Côte d'Ivoire)," Tropical Medicine \& International Health, vol. 10, no. 4, pp. 340-346, 2005.

[37] P. Cattand, J. Jannin, and P. Lucas, "Sleeping sickness surveillance: an essential step towards elimination," Tropical Medicine and International Health, vol. 6, no. 5, pp. 348-361, 2001.

[38] O. Farikou, F. Njiokou, G. Simo, T. Asonganyi, G. Cuny, and A. Geiger, "Tsetse fly blood meal modification and trypanosome identification in two sleeping sickness foci in the forest of southern Cameroon," Acta Tropica, vol. 116, no. 1, pp. 81-88, 2010.

[39] V. Mwanakasale, P. Songolo, and V. Daka, "Challenges in the control of Human African Trypanosomiasis in the Mpika district of Zambia," BMC Research Notes, vol. 6, article 180, 2013.

[40] J. W. Dennis, S. M. Durkin, J. E. Horsley Downie, L. C. Hamill, N. E. Anderson, and E. T. Macleod, "Sodalis glossinidius prevalence and trypanosome presence in tsetse from Luambe National Park, Zambia," Parasites and Vectors, vol. 7, article 378, 2014.

[41] T. L. Kohagne, M. P. M’eyi, R. Mimpfoundi, and J. F. Louis, "Entomological patterns in the human African trypanosomiasis focus of Komo Mondah, Gabon," African Health Sciences, vol. 10, no. 4, pp. 341-348, 2010.

[42] H. K. Auty, K. Picozzi, I. Malele, S. J. Torr, S. Cleaveland, and S. Welburn, "Using molecular data for epidemiological inference: assessing the prevalence of Trypanosoma brucei rhodesiense in tsetse in Serengeti, Tanzania," PLoS Neglected Tropical Diseases, vol. 6, no. 1, Article ID e1501, 2012.

[43] G. Simo, B. Silatsa, N. Flobert et al., "Identification of different trypanosome species in the mid-guts of tsetse flies of the Malanga (Kimpese) sleeping sickness focus of the Democratic Republic of Congo," Parasites and Vectors, vol. 5, article 201, 2012.

[44] M. S. Kagbadouno, M. Camara, J. Rouamba et al., "Epidemiology of sleeping sickness in Boffa (Guinea): where are the trypanosomes?" PLoS Neglected Tropical Diseases, vol. 6, no. 12, Article ID e1949, 2012.

[45] L. Lloyd and W. B. Johnson, "The trypanosome infections of tsetse flies in Northern Nigeria and a new method of estimation," Bulletin of Entomological Research, vol. 14, pp. 265288, 1924.

[46] I. Morlais, P. Grebaut, J. M. Bodo, S. Djoha, G. Cuny, and S. Herder, "Detection and identification of trypanosomes by polymerase chain reaction in wild tsetse flies in Cameroon," Acta Tropica, vol. 70, no. 1, pp. 109-117, 1998.

[47] J. O. Ouma, R. A. Masake, D. K. Masiga, S. K. Moloo, J. T. Njuguna, and J. M. Ndung'u, "Comparative sensitivity of dot-ELISA, PCR and dissection method for the detection of trypanosome infections in tsetse flies (Diptera: Glossinidae)," Acta Tropica, vol. 75, no. 3, pp. 315-321, 2000.
[48] T. Jelinek, Z. Bisoff,, L. Bonazzi et al., "Cluster of African trypanosomiasis in travelers to Tanzanian national parks," Emerging Infectious Diseases, vol. 8, no. 6, pp. 634-635, 2002.

[49] C. Waiswa, K. Picozzi, E. Katunguka-Rwakishaya, W. OlahoMukani, R. A. Musoke, and S. C. Welburn, "Glossina fuscipes fuscipes in the trypanosomiasis endemic areas of south eastern Uganda: apparent density, trypanosome infection rates and host feeding preferences," Acta Tropica, vol. 99, no. 1, pp. 23-29, 2006.

[50] V. Jamonneau, S. Ravel, M. Koffi et al., "Mixed infections of trypanosomes in tsetse and pigs and their epidemiological significance in a sleeping sickness focus of Côte d'Ivoire," Parasitology, vol. 129, no. 6, pp. 693-702, 2004.

[51] S. A. Williams, S. J. Laney, L. A. Bierwert et al., "Development and standardization of a rapid, PCR-based method for the detection of Wuchereria bancrofti in mosquitoes, for xenomonitoring the human prevalence of bancroftian filariasis," Annals of Tropical Medicine and Parasitology, vol. 96, pp. S41-46, 2002.

[52] A. M. Aransay, E. Scoulica, and Y. Tselentis, "Detection and identification of Leishmania DNA within naturally infected sand flies by seminested PCR on minicircle kinetoplastic DNA," Applied and Environmental Microbiology, vol. 66, no. 5, pp. 1933-1938, 2000.

[53] L. Berrang Ford, "Civil conflict and sleeping sickness in Africa in general and Uganda in particular," Conflict and Health, vol. 1, article 6, 2007.

[54] L. L. Joja and U. A. Okoli, “Trapping the vector: community action to curb sleeping sickness in Southern Sudan," American Journal of Public Health, vol. 91, no. 10, pp. 1583-1585, 2001.

[55] J. A. Ruiz-Postigo, J. R. Franco, M. Lado, and P. P. Simarro, "Human African trypanosomiasis in South Sudan: how can we prevent a new epidemic?" PLoS Neglected Tropical Diseases, vol. 6, no. 5, Article ID e1541, 2012.

[56] P. Lutumba, J. Robays, C. M. M. Bilenge et al., “Trypanosomiasis control, Democratic Republic of Congo, 1993-2003," Emerging Infectious Diseases, vol. 11, no. 9, pp. 1382-1388, 2005.

[57] J. R. Franco, P. P. Simarro, A. Diarra, J. A. Ruiz-Postigo, and J. G. Jannin, "The journey towards elimination of gambiense human African trypanosomiasis: not far, nor easy," Parasitology, vol. 141, no. 6, pp. 748-760, 2014.

[58] P. Mitashi, E. Hasker, F. Mbo et al., "Integration of diagnosis and treatment of sleeping sickness in primary healthcare facilities in the Democratic Republic of the Congo," Tropical Medicine and International Health, vol. 20, no. 1, pp. 98-105, 2015.

[59] P. Mitashi, P. Lutumba, C. Lumbala, P. Bessell, S. Biéler, and J. M. Ndung'u, "Improved detection of sleeping sickness cases by LED fluorescence microscopy: evidence from a prospective multi-centric study in the Democratic Republic of the Congo," Microscopy Research, vol. 3, no. 2, pp. 17-25, 2015.

[60] Z. K. Njiru, R. Traub, J. O. Ouma, J. C. Enyaru, and E. Matovu, "Detection of group 1 Trypanosoma brucei gambiense by loop-mediated isothermal amplification," Journal of Clinical Microbiology, vol. 49, no. 4, pp. 1530-1536, 2011.

[61] P. Büscher, P. Mertens, T. Leclipteux et al., "Sensitivity and specificity of HAT Sero-K-SeT, a rapid diagnostic test for serodiagnosis of sleeping sickness caused by Trypanosoma brucei gambiense: a case-control study," The Lancet Global Health, vol. 2, no. 6, pp. e359-e363, 2014.

[62] E. Matovu, A. J. Kazibwe, C. M. Mugasa, J. M. Ndungu, and Z. K. Njiru, "Towards point-of-care diagnostic and staging tools for human African trypanosomiaisis," Journal of Tropical Medicine, vol. 2012, Article ID 340538, 9 pages, 2012. 
[63] J. M. Ndung'u, S. Bieler, and G. Roscigno, “'Piggy-Backing” on diagnostic platforms brings hope to neglected diseases: the case of sleeping sickness," PLoS Neglected Tropical Diseases, vol. 4, no. 5, article e715, 2010.

[64] S. C. Welburn, I. Maudlin, and P. P. Simarro, "Controlling sleeping sickness-a review," Parasitology, vol. 136, no. 14, pp. 1943-1949, 2009.

[65] P. Solano, S. J. Torr, and M. J. Lehane, "Is vector control needed to eliminate gambiense human African trypanosomiasis?" Frontiers in Cellular and Infection Microbiology, vol. 3, article 33, 2013.

[66] F. Courtin, M. Camara, J. Rayaisse et al., "Reducing humantsetse contact significantly enhances the efficacy of sleeping sickness active screening campaigns: a promising result in the context of elimination," PLoS Neglected Tropical Diseases, vol. 9, no. 8, Article ID e0003727, 2015.

[67] I. Tirados, J. Esterhuizen, V. Kovacic et al., "Tsetse control and gambian sleeping sickness; implications for control strategy," PLoS Neglected Tropical Diseases, vol. 9, no. 8, Article ID e0003822, 2015.

[68] D. Sudarshi, S. Lawrence, W. O. Pickrell et al., "Human African trypanosomiasis presenting at least 29 years after infectionwhat can this teach us about the pathogenesis and control of this neglected tropical disease?" PLoS Neglected Tropical Diseases, vol. 8, no. 12, Article ID e3349, 2014.

[69] J. M. Lindh, S. J. Torr, G. A. Vale, and M. J. Lehane, "Improving the cost-effectiveness of artificial visual baits for controlling the tsetse fly Glossina fuscipes fuscipes," PLoS Neglected Tropical Diseases, vol. 3, no. 7, article e474, 2009.

[70] J. Esterhuizen, J. B. Rayaisse, I. Tirados et al., "Improving the cost-effectiveness of visual devices for the control of riverine tsetse flies, the major vectors of Human African Trypanosomiasis," PLoS Neglected Tropical Diseases, vol. 5, no. 8, Article ID e1257, 2011.

[71] J. B. Rayaisse, J. Esterhuizen, I. Tirados et al., "Towards an optimal design of target for tsetse control: comparisons of novel targets for the control of palpalis group tsetse in West Africa," PLoS Neglected Tropical Diseases, vol. 5, no. 9, Article ID e1332, 2011.

[72] A. P. Shaw, I. Tirados, C. T. Mangwiro et al., "Costs Of using 'Tiny Targets' to control Glossina fuscipes fuscipes, a vector of Gambiense sleeping sickness in Arua District of Uganda," PLOS Neglected Tropical Diseases, vol. 9, no. 3, Article ID e0003624, 2015.

[73] J. Rayaisse, E. Salou, F. Courtin et al., "Baited-boats: an innovative way to control riverine tsetse, vectors of sleeping sickness in West Africa," Parasites \& Vectors, vol. 8, no. 1, article 236, 2015.

[74] F. Mramba, F. Oloo, M. Byamungu et al., "Standardizing visual control devices for tsetse flies: East African species Glossina swynnertoni," PLoS Neglected Tropical Diseases, vol. 7, no. 2, Article ID e2063, 2013.

[75] F. Oloo, A. Sciarretta, M. M. Mohamed-Ahmed et al., "Standardizing visual control devices for tsetse flies: east African species Glossina fuscipes fuscipes and Glossina tachinoides," PLoS Neglected Tropical Diseases, vol. 8, no. 11, Article ID e3334, 2014.

[76] WHO, Control and Surveillance of Human African Trypanosomiasis: Report of a WHO Expert Committee, WHO Technical Report Series, WHO, Rome, Italy, 2013.

[77] N. Ndeledje, J. Bouyer, F. Stachurski et al., "Treating cattle to protect people? Impact of footbath insecticide treatment on tsetse density in Chad," PLoS ONE, vol. 8, no. 6, Article ID e67580, 2013.
[78] S. Kotlyar, "Recommendations for control of East African sleeping sickness in Uganda," Journal of Global Infectious Diseases, vol. 2, no. 1, pp. 43-48, 2010.

[79] D. Muhanguzi, K. Picozzi, J. Hatendorf et al., "Improvements on restricted insecticide application protocol for control of human and animal African trypanosomiasis in eastern Uganda," PLoS Neglected Tropical Diseases, vol. 8, no. 10, Article ID e3284, 2014.

[80] A. Neuberger, E. Meltzer, E. Leshem, Y. Dickstein, S. Stienlauf, and E. Schwartz, "The changing epidemiology of human African trypanosomiasis among patients from nonendemic countries-1902-2012," PLoS ONE, vol. 9, no. 2, Article ID e88647, 2014.

[81] E. A. Muse, I. Lejora, J. Wakibara et al., "The contribution of Tanzanian national parks in controlling the vectors of sleeping sickness," Open Journal of Ecology, vol. 5, no. 7, pp. 306-314, 2015.

[82] M. De Garine-Wichatitsky, R. A. Cheke, and D. Lazaro, "Effects of tsetse targets on mammals and birds in Kasungu National Park, Malawi," Biodiversity and Conservation, vol. 10, no. 6, pp. 869-891, 2001.

[83] I. I. Malele, "Fifty years of tsetse control in Tanzania: challenges and prospects for the future," Tanzania Journal of Health Research, vol. 13, no. 5, pp. 1-10, 2011.

[84] S. Wang, A. K. Ghosh, N. Bongio, K. A. Stebbings, D. J. Lampe, and M. Jacobs-Lorena, "Fighting malaria with engineered symbiotic bacteria from vector mosquitoes," Proceedings of the National Academy of Sciences of the United States of America, vol. 109, no. 31, pp. 12734-12739, 2012.

[85] C. B. Beard, S. L. O'Neill, R. B. Tesh, F. F. Richards, and S. Aksoy, "Modification of arthropod vector competence via symbiotic bacteria," Parasitology Today, vol. 9, no. 5, pp. 179-183, 1993.

[86] G. Bian, Y. Xu, P. Lu, Y. Xie, and Z. Xi, “The endosymbiotic bacterium Wolbachia induces resistance to dengue virus in Aedes aegypti," PLoS Pathogens, vol. 6, no. 4, Article ID e1000833, 2010.

[87] L. V. Hooper and J. I. Gordon, "Commensal host-bacterial relationships in the gut," Science, vol. 292, no. 5519, pp. 1115-1118, 2001.

[88] S. Aksoy, B. Weiss, and G. Attardo, "Paratransgenesis applied for control of tsetse transmitted sleeping sickness," in Transgenesis and the Management of Vector-Borne Disease, S. Aksoy, Ed., pp. 35-45, Landes Bioscience, Springer, 2008.

[89] R. V. Durvasula, A. Gumbs, A. Panackal et al., "Prevention of insect-borne disease: an approach using transgenic symbiotic bacteria," Proceedings of the National Academy of Sciences of the United States of America, vol. 94, no. 7, pp. 3274-3278, 1997.

[90] I. Hurwitz, H. Hillesland, A. Fieck, P. Das, and R. Durvasula, "The paratransgenic sand fly: a platform for control of Leishmania transmission," Parasites and Vectors, vol. 4, no. 1, article 82, 2011.

[91] L. R. Haines, R. E. W. Hancock, and T. W. Pearson, "Cationic antimicrobial peptide killing of African trypanosomes and Sodalis glossinidius, a bacterial symbiont of the insect vector of sleeping sickness," Vector-Borne and Zoonotic Diseases, vol. 3, no. 4, pp. 175-186, 2003.

[92] I. Maudlin, S. C. Welburn, and D. Mehlitz, "The relationship between rickettsia-like-organisms and trypanosome infections in natural populations of tsetse in Liberia," Tropical Medicine and Parasitology, vol. 41, no. 3, pp. 265-267, 1990.

[93] C. Dale and I. Maudlin, "Sodalis gen. nov. and Sodalis glossinidius sp. nov., a microaerophilic secondary endosymbiont of the tsetse fly Glossina morsitans morsitans," International Journal of Systematic Bacteriology, vol. 49, no. 1, pp. 267-275, 1999. 
[94] F. N. Wamwiri, K. Ndungu, P. C. Thande, D. K. Thungu, J. E. Auma, and R. M. Ngure, "Infection with the secondary tsetse-endosymbiont Sodalis glossinidius (Enterobacteriales: Enterobacteriaceae) influences parasitism in Glossina pallidipes (Diptera: Glossinidae)," Journal of Insect Science, vol. 14, no. 272, p. 134, 2014.

[95] N. J. Mbewe, C. Mweempwa, S. Guya, and F. N. Wamwiri, "Microbiome frequency and their association with trypanosome infection in male Glossina morsitans centralis of Western Zambia," Veterinary Parasitology, vol. 211, no. 1-2, pp. 93-98, 2015.

[96] O. Farikou, F. Njiokou, J. A. Mbida Mbida et al., "Tripartite interactions between tsetse flies, Sodalis glossinidius and trypanosomes-an epidemiological approach in two historical human African trypanosomiasis foci in Cameroon," Infection, Genetics and Evolution, vol. 10, no. 1, pp. 115-121, 2010.

[97] L. De Vooght, G. Caljon, B. Stijlemans, P. De Baetselier, M. Coosemans, and J. Van Den Abbeele, "Expression and extracellular release of a functional anti-trypanosome Nanobody in Sodalis glossinidius, a bacterial symbiont of the tsetse fly," Microbial Cell Factories, vol. 11, article 23, 2012.

[98] Y. Adam, G. Cecchi, P. M. Kgori et al., “The sequential aerosol technique: a major component in an integrated strategy of intervention against riverine tsetse in Ghana," PLoS Neglected Tropical Diseases, vol. 7, no. 3, Article ID e2135, 2013.

[99] S. Aksoy, "Sleeping sickness elimination in sight: time to celebrate and reflect, but not relax," PLoS Neglected Tropical Diseases, vol. 5, no. 2, Article ID e1008, 2011. 

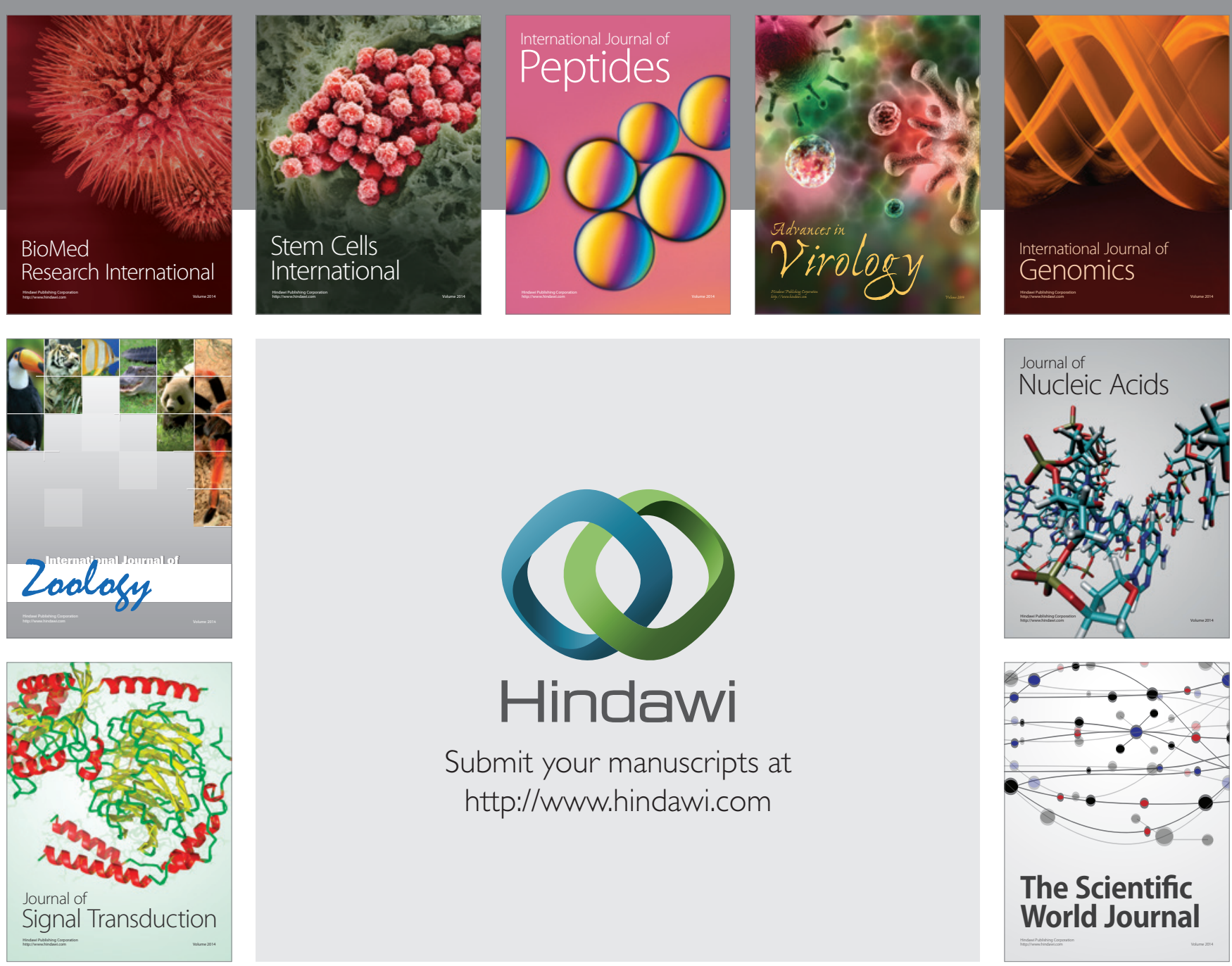

Submit your manuscripts at

http://www.hindawi.com
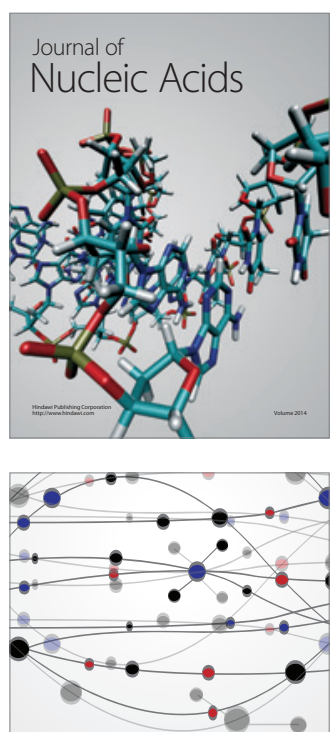

The Scientific World Journal
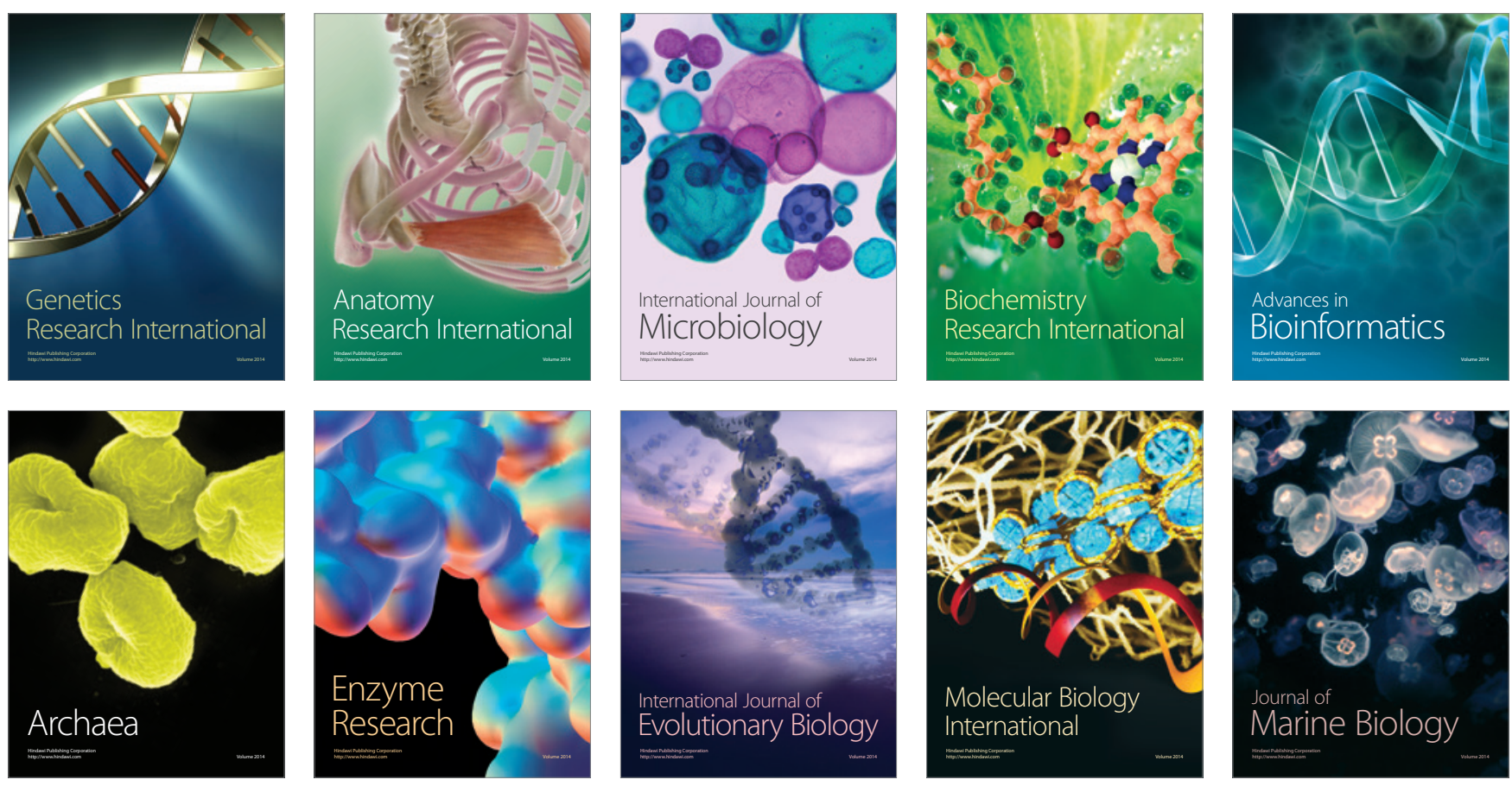